\title{
POR UM EFETIVO \\ "DEVIDO PROCESSO PENAL"
}

Gilson Bonato*

SUMARIO: 1. Introdução. 2. Conclusão. 3. Bibliografia.

SUMMARY: 1. Introduction. 2. Conclusion. 3. Bibliography.

SUMARIO: 1. Introducción. 2. Conclusión. 3. Bibliografia.

RESUMO: A discussão trazida neste artigo busca sistematizar elementos essenciais em torno do princípio do devido processo legal e sua incidência no campo penal. Traz inicialmente uma reflexão sobre a prática vivificada nos fóruns criminais e seu distanciamento do princípio em apreço. Busca, a seguir, traçar uma reflexão sobre as garantias que decorrem do devido processo e sua extensão na área criminal. A conclusão sinaliza para a necessidade de uma revisão do processo, onde o princípio do devido processo penal ganhe efetividade e a busca pela Justiça seja efetiva e não apenas formal ou aparente.

ABSTRACT: The quarrel brought in this article searchs systemize essential elements around the principle of due process of law and its incidence in the criminal field. It brings initially a vivified reflection on the practical one in criminal foruns and its distance from the principle in discussion. It searches, to make a reflection on the guarantees that follow the due process and its extension in criminal area. The conclusion signs to the necessity of a process' revision, where the principle of the due process of criminal law gains effectiveness and the search for Justice is effective, not only formal or apparent.

\footnotetext{
"Mestrando em Direito Econômico e Social pela Pontificia Universidade Católica do Paraná Professor e Coordenador do Curso de Especializaça en Direito Processual Penal da PUC/PR.
} 
RESUMEN: La discusión aportada en este artículo sistematiza elementos esenciales alrededor del principio del debido proceso legal y de su incidencia en el campo criminal. Trae inicialmente la reflexión acerca de la práctica en los foruns criminales y su distanciamiento del principio en argumento. Busca, en seguit, remontar una reflexión sobre las garantías del debido proceso y de su extensión en el área criminal. La conclusión señala para la necesidad de una revisión de esto proceso, donde el principio del debido procedimiento criminal gana eficacia y la búsqueda para la justicia es eficaz y no solamente formal o aparente.

PALAVRAS-CHAVES: Penal. Devido Processo Legal.

KEY-WORDS: Criminal. Due Process of Law.

PALABRAS-LLAVES: Penal. Debido Proceso Legal.

\section{Introdução}

Sob determinada ótica, o processo penal pode ser definido como a busca da reconstituição de fato pretérito da vida, a apreensão dos fatos como efetivamente se deram, tudo com o objetivo primordial de se fazer um julgamento de mérito sobre determinado fato, dizendo o julgador o direito a ser aplicado ao caso penal em questão.

A reconstrução do fato deve necessariamente obedecer a regras, postas anteriormente, sob pena de serem inválidos todos os atos praticados em desobediência ao comando legal ou constitucional, isto é, deve ser respeitado o devido processo legal.

A relação processual penal somente se estabelece com a participação de três sujeitos, sendo eles a parte acusadora, o juiz com jurisdição e ainda a parte acusada (ao menos potencialmente necessita-se da figura do acusado, sendo que a relação se aperfeiçoa com a sua citação válida), constituindo-se os elementos acima em pressupostos de existência do processo.

Cada parte possui funçóes específicas no processo, que devem ser desempenhadas regularmente, sob pena de nulidade, algumas relativas e outras absolutas, de acordo com o que dispõe a legislação processual vigente. 
Contudo, a prática vivificada e presenciada nos fóruns demonstra que nem sempre os princípios básicos, principalmente as garantis relativas ao acusado, têm sido respeitados, muito mais quando se trata de acusado carente ou tido como revel.

A princípio é difícil se admitir que efetivamente exista revelia no processo penal (isto porque, sempre haverá a necessidade de defesa técnica, mesmo que o acusado esteja ausente e possa ser tecnicamente considerado revel), mas na prática não é raro nos depararmos com situações de verdadeira revelia e até descaso para com o acusado, não obstante possua defensor dativo ou até constituído.

A proliferação da criminalidade e o conseqüente sem número de processos que tramitam pelas varas criminais deixam claro que a estrutura do Judiciário já não suporta mais tantos casos penais para serem acertados, dando a nítida impressão que o importante é resolver o processo, isto é, dar a solução mais simplificada para que aqueles autos ou sejam remetidos ao arquivo ou subam para o tribunal ou sejam ainda encaminhados para a vara de execução.

Não interessa mais a reconstrução do fato, não importa mais a busca da verdade material (a questão retórica é tão profunda que conseguimos desmembrar a verdade, ou melhor, conseguimos criar várias verdades); o que realmente conta é a solução para o processo em si - os autos precisam de uma solução - e não para as pessoas que estão nele envolvidas.

Neste âmbito de afazeres sem fim e de falta de tempo e de estrutura, a ausência do Estado na solução do caso é impressionante, deixando inúmeras vezes nas mãos dos esforçados estagiários ou até cartorários a dificil tarefa de conduzir o processo e até proferir decisão final de mérito.

A falta de participação do acusado no processo tem se tornado um fato habitual, que já não mais impressiona ou questiona o posicionamento do julgador ou ainda do órgão que deve promover a Justiça. Raramente se ouve na audiência a voz do defensor protestando pela presença do acusado ou a redesignação do ato. Quando muito, simplesmente pedese a "dispensa do réu", o que é de plano deferida pelo juízo, quando não é este quem sugestiona ao causídico para que a peça.

A gravidade da situação já se apresenta quando do recebimento da denúncia, onde um simples carimbo, aposto talvez pelo julgador ${ }^{1}$, substitui qualquer

Situação interessante aconteceu num processo criminal onde a denúncia foi recebida e assinada pelo próprio escrivão que fizera os autos conclusos. Numa mesma página dos autos verifica-se a assinatura do escrivĩo fazendo a conclusăo e, logo abaixo, a decisão (despacho) recebendo a denúncia e designando interrogatório, con a mesma assinatura. O mais interessante é que os autos estão em fase de alegaçôes funais e ninguém havia se apercebido do fato, passados anos de processamento do feito. 
fundamentação de tão importante decisão, sem dúvida a segunda mais importante do processo (a decisão mais importante é, por óbvio, a sentença).

Não obstante a Constituição Federal exija fundamentação das decisões $^{2}$ (e o recebimento da denúncia é uma decisão interlocutória), o Supremo Tribunal Federal já decidiu que o recebimento da denúncia trata-se de despacho, não necessitando de fundamentação ${ }^{3}$.

Referida atitude demonstra claramente o descaso para com a pessoa do acusado, que sequer tem o direito de saber os motivos do processamento do seu caso. Saliente-se que em nosso país a verdadeira pena, muitas vezes, é responder ao processo, e não a pena aplicada ao final, posto que inúmeros casos ficam anos e anos sendo processados para, ao final, receberem uma sentença extinguindo a punibilidade pela incidência do instituto da prescrição.

Poder-se-ia argumentar que o acusado tem amplamente garantido o acesso aos autos e poderá tomar conhecimento não só da acusação mas também de todas as provas (suporte probatório mínimo exigido para a propositura da ação) que contra si foram colhidas na fase inquisitória.

Ora, tal argumento não pode ser aceito, tendo em vista que cabe ao juiz analisar, quando recebe os autos inicialmente, se todas as condiçōes da ação estão presentes, a fim de não exercer um constrangimento ilegal, fazendo responder a um processo que sequer deveria ter sido instaurado. Esta é a primeira grande ausência do Estado no processo penal, sem contar, é claro, a fase inquisitorial.

Já no interrogatório constata-se uma inversão: agora o acusado é chamado a comparecer, mas não necessita de qualquer acompanhamento por defensor, sendo que muitas vezes sequer sabe o motivo de seu chamamento a juízo.

No primeiro momento em que se manifesta nos autos, geralmente a fase das alegações preliminares (iida por muitos como defesa prévia), a defesa na maioria dos casos simplesmente protesta pela produção da prova testemunhal ou, no caso de nomeação do defensor, ocorre simplesmente o preenchimento formal do ato, com uma simples negativa geral, sem qualquer pedido de produção de provas.

No tocante aos defensores públicos, cabe ressaltar a total falta de estrutura do Estado em oferecer as mínimas condições de trabalho, impossibilitando qualquer tentativa de realização de uma efetiva defesa ${ }^{4}$.

CF/88, attigo 93, IX: "Todos os julgamentos dos brgãos do Poder Judicháno serão públicos, e fundanentadas todas as decisobs, sob pena de nulidade."

RTJ 69758. Outros tribunats ja decidiram ho wesmo sentido: TJSP, Acrim 91.159. RT 662/279; TACHmSP, HC 256.318, RT 714/363; ST, RHC 1,465, 5. Tuma, DIU 16.03.1992, p. 3103; STJ, RHC 1247, RT $683 / 356$.

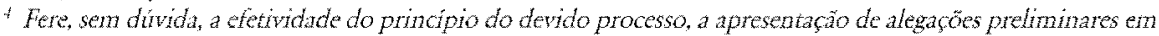
formuláro já impresso onde só é inserido o nome do acusado. Formalmente cumprese o rito processual, mas en sia efetividade, o acusado nio está tendo qualquer defesa. Sto ocorre geralmente quando há defensor datro, que nano taz nenhum contato com o acusado durane todo o processo. 
Aliás, o acusado deve ter garantido o direito de intervir no processo de forma plena e não somente na decisão final, devendo exercer a sua defesa e se manifestar em todas as oportunidades garantidas pela lei processual, sendo de extrema valia neste sentido a lição de Figueiredo Dias ${ }^{5}$.

Vale ressaltar, ainda, o descaso com que muitas vezes é considerada a prova trazida pela defesa, não sendo tão rara a ausência do órgão ministerial na audiência, simplesmente assinando os termos de depoimento posteriormente, demonstrando ainda a visão privatística, onde o processo é o palco não do debate, mas do conflitó.

A impressão que fica em muitos casos é da preocupação em se respeitar a forma estabelecida e cumprir, mesmo de que maneira superficial e aparente, o estabelecido pela lei processual, sem qualquer interesse em se garantir o efetivo contraditório e a ampla defesa. Resolve-se friamente a situação descrita no processo, mas não se resolve o caso penal, este não tem o seu efetivo acertamento, expressão esta cara para a doutrina italiana.

$O$ que se verifica é a postura de um Estado sem face, onde a impessoalidade é a característica marcante? ninguém se responsabilizando pelos atos praticados, mas justificando simplesmente que a lei foi aplicada ao caso e o dever está cumprido.

Toda a situação acima descrita fere claramente o princípio constitucional do devido processo legal, previsto na Constituição Federal de 1988, em seu artigo 5., LIV, quando assevera que "ninguém será privado da liberdade ou de seus bens sem o devido processo legaf". Referido princípio diz respeito diretamente com a razoabilidade e enquadramento das leis nas preceituações constitucionais, a aplicação destas normas jurídicas através de instrumento hábil à sua interpretação e realização e, por fim, a paridade de forças entre os sujeitos processuais, visando a igualdade substancial.

\footnotetext{
s O ilustre processualista portuguess assim se manifestou, referindo-se ao principio da audiencra: "O respeito pelo principio en epigrate inplica pois, no minimo, que se dê ao interessado oportunidade pasa intervit no debate ce se pronuxciat sobre a decisano a tomat. Quantas isso haja de acontecer é coisa que depende da concreta situaço do processo, sendo em todo caso seguro que não basta que the seja dada tal oportmidade antes da decisäo that, mas sim antes de qualquer decisão que o possa afectar juidicamente." (in Dreito Processual Denal, 1,2 volume Combra Editora, Coimbra, 1981, p. 161).

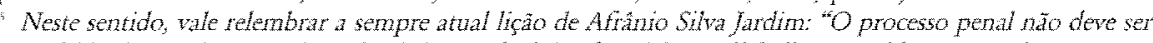
concebido dentro de uma btica pritaitstica, onde dois adversitros se dighadam movidos por sentimentos taro infornados pelo interesse público. O processo penal não deve ser transformado numa luta entre dois inimigos argutos e híbels, was sin, en meto seguro e justo para tutela dos bens e valotes protegidos pelo ordenamento juridico." (in Dircito Processual Penal, 6." ed, Rio de Janeiro: Forense, 1997, p. 304).

7 E bastante interessante verificar cono os sujetos processuats ignoram o principio da ondidade. Existe una forte resistência em apresentar alegações finats orais, tanto que em ritos que a prevejam, é comum as partes pedirem ao juz para substitui-las por memoriais, contrariando não só a previsão legal, mas fugindo ao debate oral, ao espaco do diálogos ous no dizer de Amilton Bueno de Carvalho, do local da fala e da ercuta.
} 
O princípio do devido processo legal - também denominado de princípio do processo justo ${ }^{8}$ está inserido na Lei Maior como vetor e base para os demais princípios, sendo ainda o elemento que garante a efetiva e regular aplicação do direito. Garantido expressamente somente na Constituição Federal de 1988, o princípio, entretanto, já estava implícito nas cartas anteriores, como reflexo inclusive do direito europeu e norte-americano, sendo que este último é que verdadeiramente buscou traçar os contomos atuais que o envolvem.

Segundo Rui Portanova, em sua origem o princípio em apreço visava garantir um processo ordenado para o cidadão. Para o Desembargador gaúcho, atualmente o objetivo do princípio é maior, pois, "adaptado à instrumentalidade, o processo legal é devido quando se preocupa com a adequação substantiva do direito em debate, com a dignidade das partes, com preocupações não só individualistas e particulares, mas coletivas e difusas, com, enfim, a efetiva igualização das partes no debate judicial.""

Numa análise voltada para o direito processual penal, o princípio se desdobra e diz respeito direta e prioritariamente sobre as garantias de acesso à Justiça, do juiz natural, do tratamento paritário dos sujeitos processuais, da plenitude de defesa, da publicidade dos atos processuais, da motivação dos atos decisórios e da fixação de prazo razoável de duração do processo ${ }^{10}$.

No tocante ao princípio do acesso à justica, também denominado princípio do acesso à ordem jurídica justa ${ }^{11}$, cumpre esclarecer que ele tem a perspectiva de inserir o Poder Judiciário como o local onde os cidadãos possam fazer valer os seus direitos, principalmente, na esfera do processo penal, os seus direitos de defesa, ou melhor, de plena defesa.

Para Cândido Rangel Dinamarco, "mais do que um princípio, o acesso à justiça é a síntese de todos os princípios e garantias do processo, seja a nível constitucional ou infraconstitucional, seja em sede legislativa ou doutrinária e jurisprudencial. Chega-se à idéia do acesso à justiça, que é o polo metodológico mais importante do sistema processual na atualidade, mediante o exame de todos e de qualquer um dos grandes princípios." 12

\footnotetext{
"Denominacão esta trazida por Ru PORTANOVA, en Princípios do processo civil. 3. ed. Porto Alegre: Livatia do Advogado, 1999, p. 145.

"Obra citada, p. 146 .

"Esta análise do desdobramento do principio em apreço é detheada, de forma bastante chara elicida, por Rogério Lantia Tucci e losé Rogério Cruz e Tuce, em Devido processo legal e tutela jurisdicional São Raulo : Editora Revista dos Thibunats, 1993 , p. 19.

"Expressão utilizada por Kazuo Watanabe, citado por Portanova, obra citada, p. 107.

"DINAMARCO, Candido Rangel. A instrumentalidude do processo. 5. ed. Sqo Paulo: Malheiros, 1996, p. 304.
} 
Mais do que a vítima ou do que o próprio Estado, o acusado tem direito ao processo, direito ao acesso à justiça, pois é somente através de um processo justo, respeitados os princípios que o norteiam, que se poderá dizer o direito ao caso concreto, pois qualquer outro tipo de julgamento estará fadado a cometer injustiças, posto que não respeitou os direitos básicos do cidadão. ${ }^{13}$

Ter acesso à justiça é, no processo penal, dar condições de uma acusação regular, baseada em elementos colhidos de forma imparcial e verdadeira, e ainda dar condições ao acusado de exercer plenamente o seu direito de ampla defesa, com pleno acesso a todas as provas que sejam necessárias para provar a sua inocência.

Com relação ao princípio do juiz natural em matéria penal, ninguém melhor do que Figueiredo Dias para definir a sua essência, quando afirma que "...através do qual (do princípio) se procura sancionar, de forma expressa, o direito fundamental dos cidadãos a que uma causa seja julgada por um tribunal previsto como competente por lei anterior, $e$ não ad hoc criado ou tido como competente. ${ }^{\text {n4 }}$

Estabelece ainda o autor português que o princípio possui um tríplice significado, isto é, "a) Ele põe em evidência, em primeiro lugar, o plano da fonte, só a lei pode instituir o juiz e fixar-lhe a competência. b) Em segundo lugar, procura ele explicitar um ponto de referência temporal, através deste afirmando um prinćpio de irretroactividade. a fixação do juiz e da sua competência tem de ser feita por uma lei vigente já ao tempo em que foi praticado o facto criminoso que será objecto do processo. c) Em terceiro lugar, pretende o princípio vincular a uma ordem taxativa de competência, que exclua qualquer alternativa a decidir arbitrária ou mesmo discricionariamente."15

Sempre houve no direito brasileiro previsão expressa garantindo o princípio, exceto durante o período do Estado Novo. Atualmente, a Constituição Federal o garante em seu artigo 5.. , incisos XXXVII (não haverá juízo ou tribunal de exceção) e LIII (ninguém será processado nem sentenciado senão pela autoridade competente).

A tendência atual é enfocar o princípio numa visão centrada em bases fortes. Busca-se uma visão mais aprofundada, analisando-se um segundo aspecto do juiz natural, que é o juiz constitucional. Como afirma Portanova, "por isso, entende-se que só a Constituição deva ser a fonte para fixar o juiz natural."1.6

\footnotetext{
13 Vale lenbrar aqui a liçăo de Dinamaro: "As partes têm vertademo direito ao processo, corporificado nessas regras formais do sistema processual e garantidas a nivel constitucional mediante a explícita adoça da clánsula due process of law." Obra citada, p. 304.

"DIAS, Jorge de Figueiredo. Direito processual penal. Wol L. Coimbra ; Combra Editora, 1981, p. 322 is Op. Cit, p. 322.

It Obra citada, p. 65 .
} 
O princípio do juiz natural é garantia e elemento essencial da própria jurisdição. Não é possível se compreender que as causas criminais possam ser julgadas por juizes nomeados arbitrariamente, post factum, sem que haja uma prévia determinação do juízo competente para conhecer determinado caso $^{17}$. É direito sagrado do cidadão não só saber previamente quais são as condutas criminosas, mas muito mais saber por quem será processado e julgado se vier a lhe ser imputada a prática de algum delito. ${ }^{18}$

Objeto de discussão e de polếmica tem sido também a questão do promotor natural. Apesar de tal discussão não ser objeto do presente estudo, cabe ressaltar que também o Ministério Público deve ter critérios de competência estabelecidos antes do fato, a fim de evitar nomeações posteriores que possam parecer muito mais políticas do que jurídicas. Nelson Nery Júnior esclarece, com acerto, que "estão vedadas as designações discricionárias de promotores ad hoc pelo procurador-geral de justiça, feitas a pretexto da unidade e chefia da instituição." "\$

Com relação ao tratamento paritário dos sujeitos processuais, cumpre destacar que citado princípio somente poderá ter efetividade a partir do momento em que os operadores do direito passarem a interpretar o Código de Processo Penal em consonância com a Constituição de 1988.

Faz-se necessário ressaltar que, em se tratando de ação penal pública de caráter condenatório, sem dúvida alguma, é o Ministério Público parte processual, isto é, parte em sentido processual. Desta forma, o tratamento a ser dispensado a este órgão deve ser rigorosamente o mesmo a ser dispensado à defesa, em respeito ao princípio em apreço, como também ao princípio da isonomia.

\footnotetext{
"Infelizmente a contríto do processo cint, no processo penal náo vigora o principio da identidade

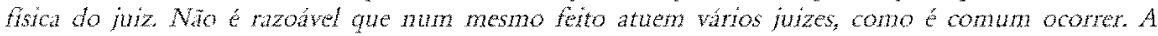
busca da verdade rél só é possivel se a instruçáo criminal for presidida por um mesmo juzz que terá então condiços de analisar diretamente as provas colhidas, isto é, o propio juiz que realiza a instrucho julgi o feito, pois á muito diferente participar da colheita da prova e simplesmente fazer uma leitura da transcriça da prova obtida.

is Exemplo charo de fermento ao princípio en questro ocorrea no Estado do Paraná quando, através de portana, o Presidente do Thbumal de Justica criou o projeto "Paraná sentenga em dia", onde os processos em

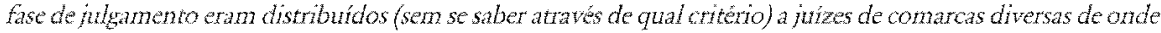
estava sendo processado o feito, para simples prolatacão de sentença. Por óbvio, portaria não pode modificar a competéncia. Mesmo que a atitude fosse tomada através de lei, também assim terina o principio, por infringir a questio temponal, isto é a determinaço do juizo competente deve ser anterior ao fata.

"NERY JUKNIOR, Nelson. Principios do processo civil na constitução federal. Säo Paulo : Revista dos Tribunais, 1092 . p. 81 .
} 
Uma rápida análise do Código de Processo Penal demonstra que inúmeros artigos trazem um tratamento desigual entre acusação e defesa, casos estes que devem ser analisados a partir dos preceitos constitucionais, com vista a estabelecer a necessária igualdade de armas entre os sujeitos processuais, para que o processo possa ser o máximo possível a expressão da verdade e de uma decisão o mais justa possível.

A tútulo exemplificativo, pode ser elencado o artigo 394, que prevê, designado o interrogatório, deva ocorrer a notificação do Ministério Público ( $e$, se for o caso, do querelante ou do assistente) para, querendo, comparecer ao ato processual. Ora, se o órgão acusador deve ter ciência do ato, também a defesa deve ser notificada para, querendo, comparecer. ${ }^{20}$

Demonstrativo do inquisitorialismo medieval é também o artigo 501 do CPP. Segundo o preceituado neste enunciado, os prazos fixados nos dois artigos anteriores (499 e 500) correrão em cartório, independentemente de intimação das partes, exceto em relação ao Ministério Público. Felizmente, muitas decisões têm sido proferidas indicando a necessidade de intimação também da defesa para a prática do ato, inclusive com carga dos autos. Entretanto, o artigo em evidência demonstra a clara desigualdade de tratamento dispensado às partes, durante a instrução criminal.

As situações elencadas, que são apenas exemplificativas, demonstram o quanto ainda o nosso processo penal é inquisitório, sem contar as inúmeras situações previstas no código que dão amplos poderes ao julgador para investigar e produzir provas. Tudo isto demonstra, de forma inequívoca, a necessidade de uma reinterpretação do sistema processual penal à luz dos princípios esculpidos na Constituição da República.

O princípio da plenitude da defesa, também denominado de ampla defesa, ou ainda princípio da mais ampla defesa, tem esta denominação porque, segundo Paulo Cláudio Tovo, o direito natural de defesa não pode sofrer qualquer restrição. Para o citado autor, o princípio é corolário direto do princípio de proteção dos inocentes ${ }^{21}$.

Merece ser destacado que a ampla defesa divide-se em autodefesa e defesa técnica. A primeira é exercida pelo próprio acusado, principalmente em seu interrogatório, e também quando auxilia o defensor, com

\footnotetext{
It É pachico o catendimento doutrinário e jurisprudencial de que o interrogutóto é ato privativo do juz e dispensa a presenç do defensor, que, na maiona dos casos, acaba seado constitudo ot nomeado neste ato. Entretanto, parecenos indspensinel a presenca do defensor no interrogatóno, não só por respeito ao principio da ampla défesa, nuas também porque o própro Código de Processo Penal prevê, en set artigo 261, que "nenhum acusado, ainda que ausente ou foragido, será processado ou julgado sem defensor". E evidente que jâ hat processo quando do interrogatóno. E mais: no dia-adra forense ano se presencia nenhum "mais afortunado" chegar a sala de audiencias sozinho, desaconpanhado de advogado. Quem chega sozinho é sempre o pobre, o preto..., isto é, os marginalizados.

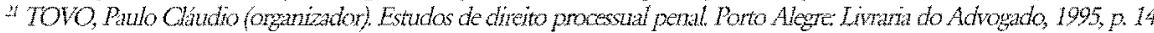


informações necessárias, esclarecimento dos fatos, escolha das pessoas que poderão testernunhar e demais elementos indispensáveis para provar os fatos que alegar em sua defesa ou desconstituir os narrados pela acusação. A presença do acusado em todos os atos processuais é um direito seu, não devendo ser encarado simplesmente como uma obrigação. Deve ter o acusado a possibilidade de escolher se quer ou não participar dos atos processuais e da instrução criminal. ${ }^{22}$

Já a defesa técnica deve sempre ser exercida privativamente por advogado regularmente inscrito na Ordem dos Advogados do Brasil. Ela deve ser exercida em todos os atos processuais, a nosso ver, inclusive no interrogatório do acusado. Tal idéia alcança fundamento no artigo 261 do Código de Processo Penal, que prevê que "nenhum acusado, ainda que ausente ou foragido, será processado ou julgado sem defensor". A relação processual se instaura com o recebimento da denúncia e se aperféçoa com a citação válida do acusado. Assim, todos os atos praticados deverão ser realizados com a presença do acusado e também do seu defensor.

Por fim, cabe destacar que a defesa técnica deve ser efetiva, não bastando cumprir os atos processuais apenas formalmente, mas a defesa deve ser substancial, por respeito ao devido processo. ${ }^{23}$ Nesta direção é a posição de Rui Portanova: "Assim, o princípio da ampla defesa, para atender perfeitamente aos termos constitucionais, mais do que nunca, deve ser cuidadosamente informado pelo princípio da efetividade social do processo. Exige-se interpretação a mais abrangente possível. Não basta o só direito de defender-se; é indispensável, para que a defesa seja plena, que a parte tenha a liberdade de oferecer alegações e meios de uma defesa efetiva. Só assim ter-se-á certa paridade de partes no processo. ${ }^{24}$

Apesar de não citado na classificação esposada no presente artigo, é de ser lembrado também o princípio do contraditório, pois intimamente ligado à ampla defesa, enquanto direito fundamental da pessoa humana. O princípio "em sintese significa que ninguém poderá ser julgado sem antes ser ouvido sobre as alegações e provas apresentadas pela parte contrária. Como garantia constitucional indica que devem-se utilizar todos os meios necessários para evitar que a disparidade de tratamento

\footnotetext{
5x Exceço al este argumento ocorre quando o acusado responde ao processo por ter sido beneficiado pela liberdade proviśria, quando então estará obrigado a comparecer a todos os atos processuals, desde que devidanente notificado para tanto, sob pena de sethe revogado o beneflcio.

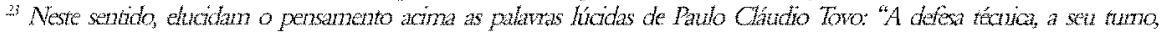

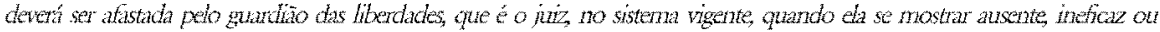

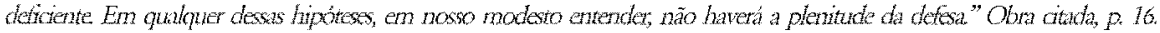
H. Obra citatis, p. 127.
} 
entre as partes, no que tange às posições no processo, possa interferir no seu resultado, comprometendo a prestação da tutela jurisdicional." 25

O princípio da motivacão dos atos decisórios está expresso na Constituição Federal em vigor (art. 93,LX). Segundo o mesmo, toda decisão judicial deve ser motivada. Com acerto, afirma Portanova que não somente as decisões judiciais, mas também as postulações da defesa e também do Ministério Público ou da parte acusadora devem conter uma motivação. ${ }^{26}$

A motivação das decisōes é uma imposição do princípio do devido processo legal, onde se busca que o julgador exteriorize as razões de sua decisão, qual a interpretação que foi dada à lei e aos fatos do caso em julgamento. Ainda com base em Portanova, é interessante ressaltar que existem inúmeros fatores que influem no convencimento do julgador, muitos até inconscientes, pois "no julgamento há premissas ocultas imperceptiveis."

É certo que o uso da linguagem pode transformar verdades em mentiras e vice-versa, ou melhor, um juiz que tenha facilidade em escrever ou um poder mais agudo no uso da linguagem, poderá convencer mais facilmente, mesmo que isto não corresponda rigorosamente aos fatos apurados durante a instrução. Ainda mais: num sistema de fundo inquisitório como o nosso, pode muito bem o juiz pré-julgar e depois ir atrás da prova, para fundar o seu convencimento, coroando tudo com uma "boa" sentença $a^{28}$.

José Carlos Barbosa Moreira já advertia, através de uma autocrítica, que os juizes preferem muito mais analisar as questões de direito, com citações de doutrina - até em língua estrangeira - e isto causa uma impressão extraordinária, do que efetivamente analisar as questões de fato, muito mais importantes para uma correta sentença. ${ }^{29}$

Portanto, a fundamentação dos atos decisórios, mesmo que decisão interlocutória, é exigência direta do princípio do devido processo. As motivações decisionais revelam respeito para com a pessoa do acusado e sua

\footnotetext{
25 BONATO, Gilson e VASCONCELOS, Rita de Cássia Corrêa de. Aspectos controveridos do contraditório nos recursos civeis. Aspectos polêtnicos e atuais dos recursos civeis e de outras formas de impugnaçã as decisões judiciais. Wol. 4. Coord. Teresa Arruda Alvim Wambier e Nelson Nery Júnior. São Paulo; Edirora Revistu dos Tribunats, 2001 , p. $508 / 509$.

2. Obia citadi, p. 247.

7 PORTANOVA, Rui. Motwacós ideologicas da sentenca. Porto Alegre: Livraria do Advogado Editora, 1992, p. 15.

* Potanova adverte sobre a necessidade da sentença, e por extentsa as outras decisoes, ser clata e de fácil compreensäo: "Oconte que, näo bastassem as difculdades do linguajar juridico, há juizes que elegem o ato sentencial palco paxa seus brilharecos vernaculares. A sentenca acaba sendo o local onde despejam suas palavras colecionadas, de pouco uso corrente e por isso pouco compreensiveis. Näo se pode esquecer também que o Poder Judicinio enata do povo. Assin, a sentença é o momento en que o juz mats responde ante o povo pelo uso que faz desse poder for isso, imprescindfyel que a sentença seja clara e convincente para que o sentinento do juiz seja comprendido sen difculdade." Obra citada, p. 249.

"BARBOSA MOREIRA, Jose CaLos. O juz e a prova RePro. V 35, 1984, p. 183.
} 
dignidade, dando-lhe, inclusive, a oportunidade de poder exercer a ampla defesa em eventual recurso, caso a decisão motivada the tenha sido desfavorável.

Por fim, o princípio da fixacão de prazo razoável de duração do processo diz respeito diretamente ao cumprimento dos prazos fixados para que o Estado dê a resposta jurisdicional ao caso penal em julgamento.

Em nosso país, como já frisado, a maior pena imposta ao acusado é a morosidade na tramitação do processo, pois causa-lhe um desgaste não só econômico, mas também social, moral e psicológico.

Mas, também, a análise não pode ser tão simplista assim. Os princípios processuais, conquista universal, não podem ser desprezados em razão de uma celeridade, que muitas vezes pode não corresponder ao ideal de justiça construído pela sociedade.

Basicamente, dois problemas afetam de maneira direta a celeridade: por um lado o grande número de demandas judiciais, fruto da realidade social do país; por outro lado, o exíguo número de magistrados e promotores de justiça, impedindo o cumprimento dos prazos fixados. Infelizmente, somente do advogado é que se exige o fiel cumprimento dos prazos. ${ }^{30}$

Assim, há que se buscar, dentro da nossa realidade, um critério de razoabilidade, para que o processo possa se desenvolver de forma rápida, entretanto respeitando os princípios básicos do processo penal, especificamente o devido processo, para que o Estado possa dar uma resposta jurisdicional rápida mas também efetiva, pois, como afirma Tucci, “a intolerável duração do processo constitui enorme obstáculo para ele cumpra, de forma efetiva e tempestiva, os seus compromissos institucionais" 31 , ou ainda, como lembrava Couture, "en el processo el tiempo es algo más que oro: es justicia." ${ }^{32}$

\section{Conclusão}

A atual estruturação do sistema processual penal brasileiro tem demonstrado o total desrespeito ao princípio do devido processo legal, mostrando-se um sistema desigual, com tratamento desigual aos sujeitos

\footnotetext{
"Näo é raro se wethicar nos autos, após a manifestaçăo ministerial on do proprio magistrado, a frase "fora do prazo legal, en raza do excesso de trabaho" ou anda "fom do prazos por estat este pronotor (fuz) designado para atender vírias varas."

"TUCC, José Rogetio Cruz e. Texpo e processo: uma analise empirica das tepercussöes do tempo na fenomenologia processual civil e penal. São Paulo. Editora Revisha dos Tibunais, 1997, p. 145.

:2 COUTURE, Eduardo. Proyecto de codigo de procedimiento civil. Montevideo : s/ed. 1945, p.37.
} 
processuais, não garantindo minimamente os direitos e garantias assegurados pela Constituição.

Uma análise da amplitude, significado e efetividade do princípio do devido processo legal demonstra a sua inaplicabilidade na prática jurídica cotidiana, sendo necessária uma mudança substancial na estruturação do processo penal brasileiro, para que este possa então estar em consonância com a Constituição da República. Há que se concluir que a prática desdiz a formulação constitucional e deforma a lógica do sistema, o que impõe a necessidade imediata de mudanças profundas não só nas leis, mas também uma conscientização dos operadores do direito, para que possa ser criada uma visão constitucional do processo, deixando de lado o legalismo e o formalismo que têm imperado nos fóruns e tribunais.

Há que se repensar o processo. Necessitamos resgatar a idéia de processo como sendo o espaço privilegiado do debate, do diálogo, da fala e da escuta $^{33}$, já que buscamos a verdade real, se é que ela efetivamente existe.

A promulgação quase diária de novas leis em nada adiantará e nada mudará se os operadores do direito continuarem os mesmos. $\mathrm{O}$ poder do intérprete é essencial no direito e as mudanças só poderão ocorrer a partir do momento em que o operador tenha consciência da nova realidade a ser criada, pois, caso contrário, o processo continuará a ser uma grande farsa. Continuaremos a ter uma caricatura de processo ${ }^{34}$.

Não é mais admissível que o processo continue sendo o espaço do conflito, sendo necessária uma urgente re-visão do mesmo, onde haja um efetivo respeito pelo princípio do devido processo legal e a busca pela reconstrução do fato não seja apenas formal ou aparente, mas o Estado realmente seja presença e não apenas uma sombra de Justiça.

\footnotetext{
*Amilon Bueno de Carvalho analisa com brihantisno a questäo, quando expoe que "o processo, instrumento do direto na diretiva da democracia, deve, portanto, estar calcado nestes dois principios: local da fala e da escuta, os quais são informadores dos principios que the sâo secundarios, contraditorio e ampla defesa. E eles tên um norte: a possibilidade das partes, autononamente, de resolveren seus conflitos, reservando-se 0 ato de império decisional a situaçes timites, ao se veriticar o caos da democnia dalogal. Mas anda assim, o aro decisório deve refetir, ante a impossibihdade da caminhada autônoma, a democracia como imposiçáo de limite ao intolerível." - Direito alternativo em novimento. 2. ed. Rio de Janeiro: Luam, 1997 p. 104

* Neste sentido é a ligáa de Cândido Rangel Dinamarco: "O que recebe destaque, agora, é a necessidade de incrementat o sistema processual, com instrumentos novos e novas técnicas pam a manusero do velhos, com adaptaça das mentalidades dos profissionais a consciencia do emprego do processo como instrumento que faca justica is partes e que seja aberto a maior nimero possivel de pessoas." Obria citada, p. 306.
} 


\section{BIBLIOGRAFIA}

BONATO, Gilson. VASCONCELOS, Rita de Cássia Corrêa de. Aspectos controvertidos do contraditório nos recursos cíveis. Aspectos polêmicos e atuais dos recursos cíveis $e$ de outras formas de impugnação às decisôes judiciais. Vol. 4. Coord. Teresa Arruda Alvim Wambier e Nelson Nery Júnior. São Paulo: Revista dos Tribunais, 2001.

CARVALHO, Amilton Bueno de. Direito alternativo em movimento. 2. ed. Rio de Janeiro: Luam, 1997.

COUTURE, Eduardo. Proyecto de codigo de procedimiento civil. Montevideo: s/ed. 1945.

DIAS, Jorge de Figueiredo. Direito Processual Penal. 1.․v vol. Coimbra: Coimbra, 1981.

DINAMARCO, Cândido Rangel. A instrumentalidade do processo. 5. ed. São Paulo: Malheiros, 1996.

JARDIM, Afrânio Silva. Direito Processual Penal. 6. ed., Rio de Janeiro : Forense, 1997.

MOREIRA, José Carlos Barbosa. O juiz e a prova. RePro. V. 35, 1984. NERY JÚNIOR, Nelson. Princípios do processo civil na constituicão federal. São Paulo: Revista dos Tribunais, 1992.

PORTANOVA, Rui. Princípios do processo civil. 3. ed. Porto Alegre: Livraria do Advogado, 1999.

- Motivaçôes ideológicas da sentença. Porto Alegre: Livraria do Advogado Editora, 1992.

TOVO, Paulo Cláudio (organizador). Estudos de direito processual penal. Porto Alegre: Livraria do Advogado, 1995.

TUCCI, José Rogério Cruz e. Tempo e processo: uma análise empírica das repercussóes do tempo na fenomenologia processual civil e penal. São Paulo : Editora Revista dos Tribunais, 1997.

TUCCI, Rogério Lauria. TUCCI, José Rogério Cruz e. Devido processo legal e tutela jurisdicional. São Paulo: Revista dos Tribunais, 1993. 